\title{
Caracterização morfológica e molecular de acessos de feijão-fava (Phaseolus lunatus L.) ${ }^{1}$
}

\author{
Walma N. R. Guimarães ${ }^{2}$, Luiza S. S. Martins ${ }^{3}$, Edson F. da Silva ${ }^{3}$, Gabriela de M. G. Ferraz ${ }^{4}$ \& Francisco J. de Oliveira ${ }^{5}$
}

\section{RESUMO}

O objetivo deste trabalho foi analisar a diversidade genética de 22 acessos de feijão-fava (Phaseolus lunatus L.) oriundos dos Estados do Ceará, Paraíba e Pernambuco, que compõem a Coleção de Germoplasma do Departamento de Agronomia da UFRPE, através de marcadores RAPD e caracterizar quatorze desses genótipos através de marcadores morfológicos. Para caracterização da variabilidade genética foram utilizados 60 locos polimórficos. Pela análise de agrupamento verificou-se a formação de dois grupos, quatro subgrupos e elevada variabilidade genética entre os acessos. Os acessos mais próximos geneticamente, foram FA-01 e FA-02, provenientes do Ceará, com grau de similaridade de 85,4\%, e os mais distantes, foram FA-07 e FA-20 oriundos do Ceará e Pernambuco, respectivamente, com grau de similaridade de 35,9\%. Quanto à caracterização morfológica, observou-se que o genótipo FA-13 se destacou dos demais, por apresentar maiores valores no peso das sementes, no número de sementes por vagem, comprimento e largura da vagem, enquanto o genótipo FA-16 apresentou menores valores de peso de 100 sementes, sementes muito pequenas, menor número de vagem por planta, menor comprimento de vagem e menor produção de semente por planta.

Palavras-chave: diversidade genética, fava, marcadores RAPD, marcadores morfológicos

\section{Morphological and molecular characterization of accessions of lima-beans (Phaseolus lunatus L.)}

\begin{abstract}
The objective of this work was to analyze genetical diversity of twenty-two accessions of lima-beans (Phaseolus lunatus L.), coming from the States of Ceará, Paraíba and Pernambuco, Brazil, part of the Germoplasm Collection of the Agronomy Department of Federal Rural University of Pernambuco, by RAPD markers, as well as to characterize fourteen of these genotypes by means of morphological markers. To characterize the genetic variability, sixty polymorphic loci were used. By the sample analysis the formation of two groups and four subgroups was observed and high genetic variability among the accessions was noticed. The genetically closer genotypes were FA-01 and FA-02, from Ceará State, with 85\% of similarity, and the less similar ones were FA-07 and FA-20, from Ceará and Pernambuco States, respectively, with 35.9\% similarity. Related to the morphological characterization, it was noticed that the genotype FA-13 in comparison to others presented higher values of seed weight, number of seeds per pod, length and width of pod, while the FA-16 genotype showed lower values for weight of one hundred seeds, very small seeds, lower number of pods per plant, lower length of pod and lower production of seed per plant.
\end{abstract}

Key words: genetic diversity, lima-beans, RAPD markers, morphological markers

1 Parte da Dissertação de Mestrado da primeira autora, apresentada à UFRPE

${ }^{2}$ Mestranda do PPGAMGP/UFRPE. Av. Dom Manoel de Medeiros s/n, Bairro Dois Irmãos, CEP 52171-900, Recife, PE. Fone: (81) 3320-6313. Fax: (81) 3320-6300.

E-mail: walmalamo@gmail.com

${ }^{3}$ Departamento de Biologia/UFRPE. Fone: (81) 3320-6313. Fax: (81) 3320-6300. E-mail: luiza@ufrpe.br; edson@ufrpe.br

${ }^{4}$ Graduanda em Ciências Biológicas, bolsista do PIBIC-CNPq-UFRPE. E-mail: gabrielamferraz@click21.com.br

${ }^{5}$ Departamento de Agronomia/UFRPE. Fone: (81) 3320-6253. Fax: (81) 3320-6200. E-mail: franseol@uol.com.br 


\section{INTRODUÇÃO}

A família Fabaceae, uma das maiores entre as dicotiledôneas, com 643 gêneros, reúne 18.000 espécies distribuídas em todo o mundo, estando concentrada nas regiões tropicais e subtropicais (Broughton et al., 2003). A espécie Phaseolus lunatus L., também conhecida como feijão-fava ou feijãolima, é cultivada na América do Norte, na América do Sul, na Europa, no leste e oeste da África e no sudeste da Ásia (Baudoin, 1988).

No Brasil, apesar de cultivada em todos os Estados e de apresentar capacidade de adaptação mais ampla que o feijão-comum (Phaseolus vulgaris L.), o cultivo do feijão-fava ainda tem pouca relevância. Acredita-se que as principais razões para o cultivo relativamente limitado, sejam: a maior tradição de consumo do feijão-comum, o paladar do feijãofava e o seu tempo de coç̧ão mais longo. A importância econômica e social se deve principalmente à sua rusticidade em regiões semi-áridas do Nordeste brasileiro, o que possibilita prolongar a colheita em período seco (Azevedo et al., 2003). Os grãos verdes e secos, as vagens verdes e as folhas do feijão-fava, podem ser consumidos pelo homem; trata-se de uma das principais leguminosas cultivadas na região tropical, que apresenta potencial para o fornecimento de proteína vegetal à população e diminuição da dependência, quase exclusiva, do feijão-comum do grupo carioca (Vieira, 1992). De acordo com Oliveira et al. (2004), o feijão-fava é, hoje, uma alternativa de renda e fonte alimentar para a população da região Nordeste do Brasil, que o consome sob a forma de grãos maduros ou verdes. Ainda segundo os mesmos autores, o Estado da Paraíba, onde é cultivado em quase todas as microrregiões, vem-se destacando como um dos maiores produtores nacionais.

A caracterização morfológica fornece uma série de informações a respeito da variabilidade genética de cada acesso estudado. Esses dados auxiliam na caracterização de germoplasma, possibilitando grandes avanços na descrição da divergência genética entre acessos. A variabilidade genética só pode ser eficientemente utilizada se for devidamente avaliada e quantificada, sendo a descrição das introduções ou acessos fundamental para a manutenção e exploração do potencial das coleções; tal caracterização pode ser feita por meio de marcadores ou descritores morfológicos e/ou moleculares (Singh, 2001).

Diversos autores (Nienhuis et al., 1995; Vera et al., 1999; Beebe et al., 2000; Eichenberg et al., 2000) têm utilizado marcadores RAPD no agrupamento de genótipos de feijão, de acordo com o centro de domesticação sendo, portanto, eficazes na avaliação da variabilidade genética dentro e entre populações de plantas e na elucidação de parentescos entre acessos. O uso de marcadores moleculares representa uma ferramenta significativa em programas de melhoramento genético em plantas, pois oferece possibilidades no manejo de coleções, permite a comparação entre indivíduos, identificando duplicatas, além de possibilitar a classificação do germoplasma em grupos de interesse para os diferentes programas de melhoramento (Eichenberg et al., 2000).

A seleção assistida por marcadores moleculares, pode permitir a identificação da presença ou ausência de gene(s) ligado(s) a características específicas para fins de melhoramento, com a vantagem de se fazer as análises antes da realização de experimentos de campo; assim, diminuem-se os custos com adubação, capina, irrigação, além de redução no número de gerações necessárias no desenvolvimento de variedades. Atualmente, há inúmeros tipos de marcadores moleculares que se diferem quanto à habilidade em detectar diferenças entre indivíduos, custo, facilidade de uso, consistência e repetibilidade (Ferreira \& Grattapaglia, 1998).

O presente trabalho teve como objetivo avaliar a variabilidade genética de 22 acessos de feijão-fava (P. lunatus L.) coletados nos Estados do Ceará, Paraíba e Pernambuco, que compõem a Coleção de Germoplasma do Departamento de Agronomia da Universidade Federal Rural de Pernambuco, por meio de marcadores RAPD, e caracterizar 14 desses genótipos, por meio de marcadores morfológicos.

\section{MATERIAL E MÉTODOS}

A condução do experimento de campo foi realizado na área experimental do Departamento de Agronomia da Universidade Federal Rural de Pernambuco, Município do Recife ( $8^{\circ} 10^{\prime} 52^{\prime \prime} \mathrm{S}, 34^{\circ} 54^{\prime} 47^{\prime}$ ' W, $2 \mathrm{~m}$ de altitude), no ano agrícola 2004. Utilizaram-se 22 acessos coletados junto aos pequenos produtores dos Municípios dos Estados do Ceará (Quixeramobim), Paraíba (Campina Grande) e Pernambuco (Gravatá) que constituem a coleção de germoplasma da Área de Fitotecnia da UFRPE, relacionados na Tabela 1. Todos os

Tabela 1. Relação dos acessos de P. Lunatus, nomes populares, procedência e cor do tegumento da Coleção de Germoplasma do Departamento de Agronomia da UFRPE, utilizados na caracterização molecular e morfológica

\begin{tabular}{cccl}
\hline Denominação & Nome popular & Procedência & Cor do tegumento \\
\hline FA-1 & Orelha-de-velho & Quixeramobim, CE & Rajado branco com preto \\
\hline FA-2 & - & Quixeramobim, CE & Branca \\
\hline FA-3 & - & Quixeramobim, CE & Branca mancha alaranjada \\
\hline FA-4 & - & Quixeramobim, CE & Creme com marrom \\
\hline FA-5 & Manteiga & Quixeramobim, CE & Creme \\
\hline FA-6 & - & Quixeramobim, CE & Preta \\
\hline FA-7 & - & Quixeramobim, CE & Branca \\
\hline FA-8 & - & Quixeramobim, CE & Vermelha \\
\hline FA-9 & - & Quixeramobim, CE & Branco com preto \\
\hline FA-11 & - & Quixeramobim, CE & Rajado branco com vermelho \\
\hline FA-13 & Olho-de-ovelha & Quixeramobim, CE & Branco com preto \\
\hline FA-14 & - & Quixeramobim, CE & Marrom com branco \\
\hline FA-15 & Alva & Quixeramobim, CE & Branca \\
\hline FA-16 & - & Gravatá, PE & Vinho \\
\hline FA-17 & - & Gravatá, PE & Rajado marrom com roxo \\
\hline FA-18 & - & Gravatá, PE & Roxo com creme \\
\hline FA-19 & - & Gravatá, PE & Rajado marrom com roxo \\
\hline FA-20 & - & Gravatá, PE & Rajado marrom com roxo \\
\hline FA-21 & - & Quixeramobim, CE & Rajado branco com marrom \\
\hline FA-24 & - & Campina Grande, PB & Marrom com creme \\
\hline FA-25 & - & Campina Grande, PB & Preto com creme \\
\hline FA-27 & - & Campina Grande, PB & Branca \\
\hline
\end{tabular}


acessos foram avaliados quanto à variabilidade genética, por meio de marcadores RAPD, e 14 desses: FA-1, FA-3, FA-7, FA-8, FA-9, FA-11, FA-13, FA-16, FA-17, FA-18, FA-19, FA-20, FA-25 e FA-27, por terem completado o ciclo reprodutivo, também foram avaliados em relação a caracteres morfológicos.

\section{Caracterização molecular}

As análises moleculares foram realizadas no Laboratório de Bioquímica e Seqüenciamento de DNA Prof ${ }^{a}$ Tânia Falcão, do Departamento de Biologia da Universidade Federal Rural de Pernambuco.

O DNA foi extraído a partir de folhas jovens dos 22 acessos, coletadas no décimo sexto dia após o plantio. O protocolo de extração de DNA seguiu metodologia proposta por Doyle \& Doyle (1990) com as modificações propostas por Martins et al. (2004). Cerca de $300 \mathrm{mg}$ de folhas jovens foram congelados e macerados em almofariz de porcelana, em presença de nitrogênio líquido e acondicionados em microtubos de 2,0 mL; ao material macerado adicionaram-se $700 \mu \mathrm{L}$ de tampão de extração (4,9 mL de CTAB 5\%; 6,9 mL $\mathrm{NaCl}$ 5M; 0,9 mL EDTA 0,5 M; 2,49 mL Tris-HCl (pH 8,0) 1,0 M; 24,9 $\mu \mathrm{L}$ ß-mercaptoetanol).

O DNA extraído de cada amostra foi quantificado em gel de agarose a $0,8 \%$ por comparação visual da intensidade de fluorescência das bandas comparadas com as do DNA fago (40, 20, 10 e $5 \mathrm{ng}$ de DNA fago); para tanto aplicaram-se, em cada poço do gel, $5 \mu \mathrm{L}$ da amostra e $2 \mu \mathrm{L}$ do tampão de corrida. Em um dos poços foram aplicados $2 \mu \mathrm{L}$ do marcador de DNA Ladder-1 Kb, PLUS e, após aplicação, realizouse uma eletroforese horizontal de imersão a $100 \mathrm{~V}$, até que a linha de fronte chegasse a $5 \mathrm{~cm}$ de corrida. $\mathrm{O}$ gel foi corado em solução de brometo de etídio (10 $\left.\mathrm{mg} \mathrm{mL}^{-1}\right)$ e visualizado sobre luz ultravioleta. Após a quantificação o DNA foi diluído, ficando com a concentração de $25 \mathrm{ng} \mathrm{mL}^{-1}$ para realização das reações.

Realizaram-se as reações de amplificação obedecendo protocolo estabelecido por Martins et al. (2004). As amplificações, em um volume final de $15 \mu \mathrm{L}$, continham: $25 \mathrm{mg} \mathrm{mL}^{-1}$ de DNA genômico; $10 \mathrm{mM}$ Tris- $\mathrm{HCl}$ (pH 8,3); $50 \mathrm{mM} \mathrm{KCl} ; 100 \mathrm{mM}$ de cada um dos dNTPs; 1,4 mM de $\mathrm{MgCl}_{2} ; 10$ pmol de primer (oligonucleotídeos decâmeros de seqüência aleatória) e uma unidade de Taq DNA polimerase e água estéril para que se completasse o volume final da reação. Controles foram feitos pela substituição do DNA genômico, por água estéril.

De início, empregaram-se 37 primers da Operon Techonologies e da Invitrogen ${ }^{\mathrm{TM}}$ Life Technologies, a saber: OP-AA02, OP-A12, OP-A15, OP-A18, OP-A20, OP-B10, OP-B12, OP-B13, OP-B18, OP-C08, OP-C15, OP-C17, OP-D03, OP-D05, OP-D06, OP-D07, OP-D08, OP-D13, OP-E02, OP-F04, OP-T17, B-01, B-02, B-05, B-06, B-07, B-08, B-09, B-10, C-02, C-03, C-04, C-05, C-06, C-07, C-08 e C-09, baseados no trabalho de Martins (1999).

As amplificações foram realizadas através de termociclador (Programmable Thermal Controller, Modelo PTC$100^{\mathrm{TM}}$ ), no qual as amostras foram submetidas a ciclos de amplificações, usando-se programa composto por 40 ciclos, sendo cada ciclo formado de uma etapa de desnaturação a $94{ }^{\circ} \mathrm{C}$, durante $15 \mathrm{~s}$, uma etapa de anelamento a $35^{\circ} \mathrm{C}$ por $30 \mathrm{~s}$, uma etapa de extensão a $72{ }^{\circ} \mathrm{C}$ por $60 \mathrm{~s}$, seguida de uma etapa de alongamento a $72{ }^{\circ} \mathrm{C}$ por $7 \mathrm{~min}$, finalizando com $4{ }^{\circ} \mathrm{C}$, por tempo indeterminado. Os produtos das amplificações foram separados por eletroforese, a uma migração de $100 \mathrm{~V}$ por $2 \mathrm{~h}$, em gel de agarose a 1,2\%, imerso em tampão TAE 1x (Trisma-Base 90 mM; EDTA 1 mM, pH 8,0). Terminada a corrida, os géis foram corados em solução de brometo de etídio (10 $\left.\mathrm{mg} \mathrm{mL}^{-1}\right)$, durante 2 min e colocados, em seguida, 15 min, em água destilada; em seqüência, foram fotografados com câmara digital. O marcador DNA Ladder-1 Kb, PLUS, foi utilizado como padrão para determinação do peso molecular dos respectivos fragmentos de DNA amplificados, os quais foram visualizados sob luz ultravioleta.

\section{Análise dos dados obtidos}

Mediante a interpretação dos géis, os dados moleculares foram tabulados conforme presença (1) ou ausência (0) de cada fragmento específico de DNA amplificado, gerado por primers em cada genótipo, para serem usados no estudo de diversidade genética. As similaridades genéticas entre os genótipos foram estimadas usando-se o coeficiente de Jaccard (Rohlf, 1992), no programa Numerical Taxonomy and Multivariate Analysis System-NTSYS, versão 1.70, Exeter software, NY, USA; enfim, obteve-se o dendrograma por meio do programa NTSYS-pc, usando-se a opção Unweighted Pair-Group Method Arithmetic Average - UPGMA.

\section{Caracterização morfológica}

Os acessos foram semeados em covas com espaçamento de 1,5 x 2,0 m. Em cada cova foram plantadas quatro sementes realizando-se, após oito dias, o replantio de mais quatro sementes. Oito semanas após a germinação realizou-se o desbaste deixando-se uma planta por cova. No plantio aplicou-se $1,5 \mathrm{~g}$ de $\left(\mathrm{NH}_{4}\right)_{2} \mathrm{SO}_{4}$ (sulfato de amônio) nas covas, visando a um bom desenvolvimento da planta e se fez o controle de plantas invasoras por meio de duas capinas mecânicas no período anterior ao florescimento e a irrigação com regadores manuais, durante todo o ciclo da cultura; as plantas de hábito de crescimento indeterminado foram tutoradas com bambu.

Os dados referentes aos caracteres agronômicos e morfológicos de 14 acessos foram tomados em uma planta com base nos descritores para feijão ( $P$. vulgaris L.): (1) hábito crescimento: determinado (D) ou indeterminado (I); (2) cor do caule (CC): determinada de acordo com a presença e a intensidade de pigmentação (antociano) podendo ser: verde sem pigmentação (VSP), verde com pigmentação tênue (VPT) e verde com pigmentação intensa (VPI), (CIAT, 1976); (3) diâmetro do caule (DC): realizado com auxílio de um paquímetro entre os segundo e terceiro nós; (4) pêlo do caule (PC), pode ser glabro ou sem pêlos (G) ou piloso (P); (5) número de nós até $1 \mathrm{~m}$ de altura da planta (NUP): por meio de contagem a partir do primeiro nó, após a cicatriz da primeira folha até $1 \mathrm{~m}$, utilizando-se fita métrica; (6) número de nós até o ramo principal (NRP): contagem a partir do 
primeiro nó, após a cicatriz da primeira folha até o ramo principal; (7) forma da folha (FF): acuminada (A), bruscamente acuminada (BA) e longamente acuminada (LA); (8) cor da folha (F): verde claro (VC), verde normal (VN) e verde escuro (VE); (9) área foliar (AF): em $\mathrm{cm}^{2}$, efetuada no início da frutificação, definido como o momento em que cerca de $50 \%$ das plantas apresentavam uma ou mais vagens, medindo-se o maior comprimento $\left(\mathrm{C}_{\max }\right)$ e a maior largura $\left(\mathrm{L}_{\max }\right)$ do folíolo central da folha, situada na altura do sexto nó e estimada através da fórmula $\mathrm{AF}=0,5012 \times \mathrm{C}_{\max } \times \mathrm{L}_{\max }$, segundo Araújo \& Paiva, citados por Oliveira et al. (2003); (10) borda da lâmina foliar (BLF): lisa (L) ou serrilhada (S); (11) textura da lâmina foliar (TLF): tenra (T), rígida (R) ou coriácea (C); (12) cor da flor: branca (B), branco-amarelado (BA), amarelo-branco (AB), lilás (L) observação feita nas primeiras horas da manhã; (13) cor da vagem (CRV): verde uniforme (VU), verde com manchas vermelhas (VMV), verde com manchas violáceas (VMVL), amarela uniforme (AU), amarela com pequenas manchas vermelhas (AMV) e amarela com manchas roxas (AMR), (Vilhordo \& Müller, 1981); (14) número de vagens por planta (NVP): considerando-se a quantidade total de frutos produzidos e colhidos por planta; (15) comprimento da vagem (CV): em cm, determinado considerando-se a média de todas as vagens produzidas em cada planta; (16) largura da vagem (LV): utilizando-se o paquímetro, em mm; (17) espessura da vagem (EV): por meio de paquímetro, em mm; (18) cor do tegumento (CT): rajado de branco e preto (RBP), branco com manchas alaranjadas (BA), branca (B), vermelha (V), branca com preto (BP), rajado branco com vermelho (RBV), vinho (VI), rajado marrom com roxo (RMR), roxo com creme (RC), preto com creme (PC); (19) tamanho da semente (TS): grande (G), média (M), normal (N) e muito pequena (MP); (20) peso de cem sementes (PCS): em grama, determinado tomando-se 100 sementes de cada planta; (21) forma da semente (FS): por meio dos coeficientes J (comprimento/largura) e H (espessura/largura), descrito por Puerta Romero, citado por Vilhordo et al. (1996), elíptica/achatada (EA), elíptica semicheia (EC), esférica/achatada (SA); (22) número de vagens por planta (NVP): correspondeu à quantidade total de frutos produzidos e colhidos por planta; (23) número de sementes por vagem (NSV): tomado em dez vagens por planta; (24) produção semente por planta $(\mathrm{P})$ : em grama, tomado em balança com precisão de $0,01 \mathrm{~g}$.

\section{RESULTADOS E DISCUSSÃO}

Dos 37 primers testados, selecionaram-se 16 os quais, por outro lado, geraram produtos de amplificação mais consistentes (Tabela 2). Obteve-se o total de 76 bandas, sendo 60 polimórficas e 16 monomórficas correspondendo, assim, a 78,94\% de regiões de bandas polimórficas. Os primers que geraram maior número de bandas polimórficas, foram o OP-C15, OP-E02, OP-E04, OP-A18, C-05 e C-06 (Figura 1). Martins et al. (2004), utilizando a técnica de RAPD para discriminar quatro genótipos de Phaseolus vulgaris L. resistentes e suscetíveis ao fungo Phaeoisariopsis griseola, observaram que o primer OP-C15 amplificou regiões de bandas de DNA presente apenas nos genitores resistentes; já Fofana et al. (1997), ao utilizarem a mesma técnica, constataram que, dentre os 11 primers utilizados, o OP-D05 e o OP-D08, também empregados neste trabalho, foi possível se distinguir 17 acessos entre os grupos sieva e batata de feijão-fava.

Tabela 2. Relação de primers e polimorfismo de bandas apresentados para genótipos de feijão-fava (P. lunatus L.)

\begin{tabular}{|c|c|c|c|c|c|}
\hline \multirow{2}{*}{ Ordem } & \multirow{2}{*}{ Primers } & \multirow{2}{*}{$\begin{array}{c}\text { Sequiências } \\
5^{\prime}-3^{\prime}\end{array}$} & \multicolumn{2}{|c|}{ Regiões de bandas } & \multirow{2}{*}{ Tota } \\
\hline & & & Poli-mórfica & Mono-mórfica & \\
\hline 1 & OP-A18 & AGGTGACCGT & 5 & 0 & 5 \\
\hline 2 & OP-B13 & TTCCCCCGCT & 3 & 0 & 3 \\
\hline 3 & OP-C15 & GACGGATCAG & 7 & 0 & 7 \\
\hline 4 & OP-C17 & TTCСССССАG & 2 & 0 & 2 \\
\hline 5 & OP-D05 & TGAGCGGACA & 1 & 1 & 2 \\
\hline 6 & OP-D06 & ACCTGAACGG & 3 & 4 & 7 \\
\hline 7 & OP-D08 & GTGTGCCCCA & 3 & 0 & 3 \\
\hline 8 & OP-E02 & GGTGCGGGAA & 6 & 3 & 9 \\
\hline 9 & OP-F04 & GGTGATCAGG & 6 & 0 & 6 \\
\hline 10 & B-02 & AGCGTGTCTG & 4 & 0 & 4 \\
\hline 11 & B-09 & GGAAGTCGCC & 1 & 0 & 1 \\
\hline 12 & C-02 & AATCGGGCTG & 4 & 2 & 6 \\
\hline 13 & C-03 & GAACGGACTC & 2 & 3 & 5 \\
\hline 14 & C-04 & AAAGCTGCGG & 3 & 0 & 3 \\
\hline 15 & C-05 & GACGGATCAG & 5 & 0 & 5 \\
\hline \multirow[t]{2}{*}{16} & $\mathrm{C}-06$ & GGACCCAACC & 5 & 3 & 8 \\
\hline & \multicolumn{2}{|c|}{ Totais locos } & 60 & 16 & 76 \\
\hline
\end{tabular}

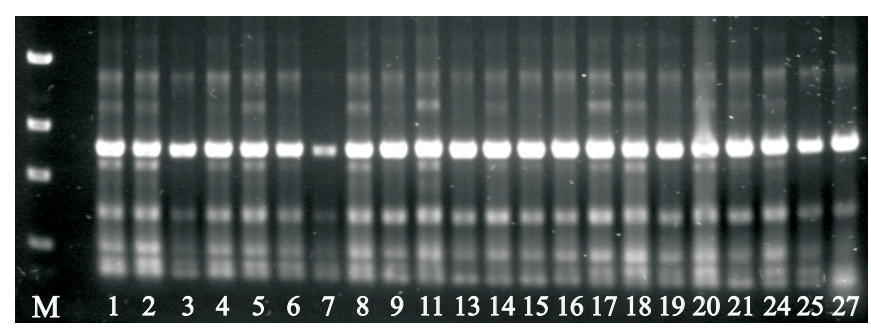

Figura 1. Análise eletroforética do produto de amplificação dos 22 acessos de feijão-fava (P. lunatus L.) utilizando-se o primer C-06: 1. FA-01; 2. FA-02; 3. FA-03; 4. FA-04; 5. FA-05; 6. FA-06; 7. FA-07; 8. FA-08; 9. FA-09; 10. FA-11; 11. FA-13; 12. FA-14; 13. FA-15; 14. FA-16; 15. FA-17; 16. FA-18; 17. FA-19; 18. FA-20; 19. FA-21; 20. FA-24; 21. FA-25 e 22. FA-27. $\mathrm{M}=$ marcador DNA Ladder $-1 \mathrm{~Kb}$, PLUS

Por meio do dendrograma construído a partir dos 22 genótipos analisados molecularmente (Figura 2), verificou-se haver dois grupos principais e quatro subgrupos. Um grupo formado pelos genótipos: FA-01, FA-02, FA-05, FA-07, FA-08, FA-11, FA-14, FA-16, FA-18 e FA-24 e outro grupo constituído por: FA-03, FA-04, FA-06, FA-09, FA-13, FA-15, FA-17, FA-19, FA-20, FA-21, FA-25 e FA-27. Pelos grupos formados não se distinguem os acessos por procedência, ou seja, acessos oriundos de Pernambuco, Paraíba e Ceará, que compõem os dois grupos; isto ocorre freqüentemente com culturas em que predomina o cultivo de variedades crioulas, como o feijão-fava e ocorre intercâmbio de sementes entre os agricultores; entretanto, outros autores, como Nienhuis et 


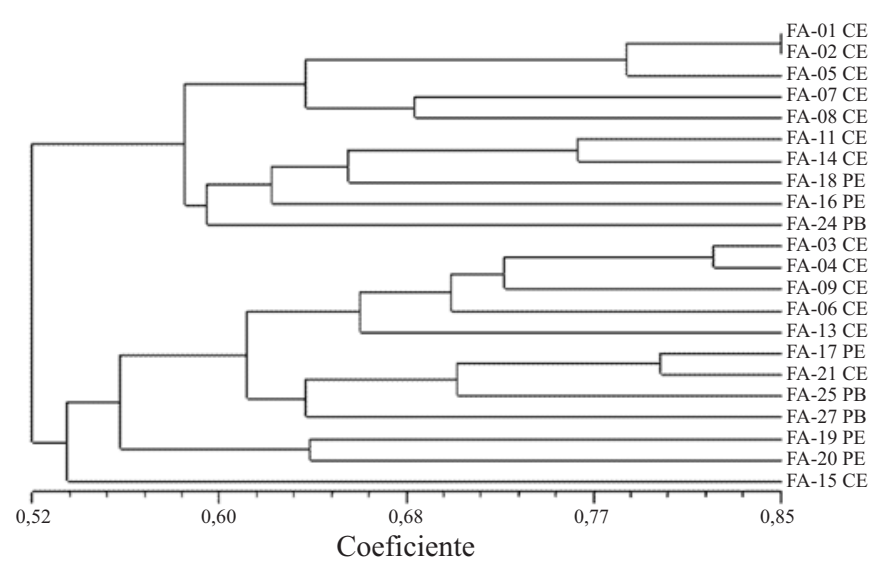

Figura 2. Análises de agrupamento dos 22 genótipos de feijão-fava $(P$ lunatus L.), obtidos pelo programa NTSYS-pc através da opção UPGMA (Unweighted Pair-Group Method Arithmetic Average)

al. (1995), ao avaliarem a distância genética através de marcadores RAPD de 65 acessos de P. lunatus L., sendo 11 cultivados por pequenos produtores e 54 oriundos de bancos de germoplasma, conseguiram agrupá-los por tamanho de semente e por origem geográfica.

Quanto à cor do tegumento, os acessos FA-17, FA-19 e FA-20 de sementes rajadas de marrom com roxo, ficaram no mesmo grupo e os acessos FA-19 e FA-20, pertencentes ao mesmo subgrupo. Enquanto FA-17 (rajada marrom com roxo) e FA-21 (rajada branco com marrom) diferindo na cor, estão também em um mesmo subgrupo, com grau de similaridade de 0,800 (80\%).

Os dois genótipos mais próximos foram FA-01 e FA-02, provenientes do Ceará, com grau de similaridade de 0,854 $(85,4 \%)$ e os mais distantes foram FA-07 e FA-20, do Ceará e Pernambuco, respectivamente, com grau de similaridade 0,359
(35,9\%) (Tabela 3). Os dados de similaridade, ou divergência genética, podem ser úteis em programa de melhoramento genético, já que é um dos parâmetros utilizados na escolha de genitores para realização de cruzamentos. A análise de agrupamentos de acessos de $P$. lunatus, usando-se marcadores moleculares para avaliação de relações filogenéticas, foi efetuada em trabalhos como o de Lioi \& Galasso (2002) que, através de marcadores de microssatélites, conseguiram separar os acessos de origem mesoamericanos daqueles de origem andina, agruparam em dois grupos principais o grupo 1 , o Mesoamericano (provenientes do Iraque, Nigéria, El Salvador, Brasil, México, Belize, Guatemala, Costa Rica, Peru, Colômbia e Argentina) e o grupo 2, o Andino (provenientes da Zâmbia, Peru e Equador). Fofana et al. (1997) e Caicedo et al. (1999), também observaram esta separação dos grupos Mesoamericano e Andino de feijão-fava (P. lunatus L.) utilizando marcador RAPD e AFLP, respectivamente.

As observações dos 14 acessos, quanto às características morfoagronômicas, estão relacionadas nas Tabelas 4 e 5. Ressalta-se que os dados obtidos foram tomados em um indivíduo de cada acesso; portanto, são representativos apenas para os caracteres de herança monogênica, como: hábito de crescimento (Sax, 1926; Bliss, 1971; Miranda, 1973; Freire Filho, 1980; Halvankar \& Patil, 1994), presença ou ausência de pêlos no caule (Ospina, 1981), forma da folha (Halvankar \& Patil, 1994), cor da vagem (Halvankar \& Patil, 1994) e cor do tegumento (Khattak et. al, 1999). Em relação aos caracteres de herança poligênica ou que apresentam interações gênicas, os dados do presente trabalho podem apenas auxiliar na realização de outras pesquisas de caracterização utilizando-se o delineamento experimental adequado.

Conforme os dados apresentados na Tabela 4, 13 genótipos apresentaram hábito de crescimento indeterminado,

Tabela 3. Similaridade genética entre os 22 genótipos de $P$. lunatus L., feijão-fava da coleção de germoplasma do Departamento de Agronomia da UFRPE

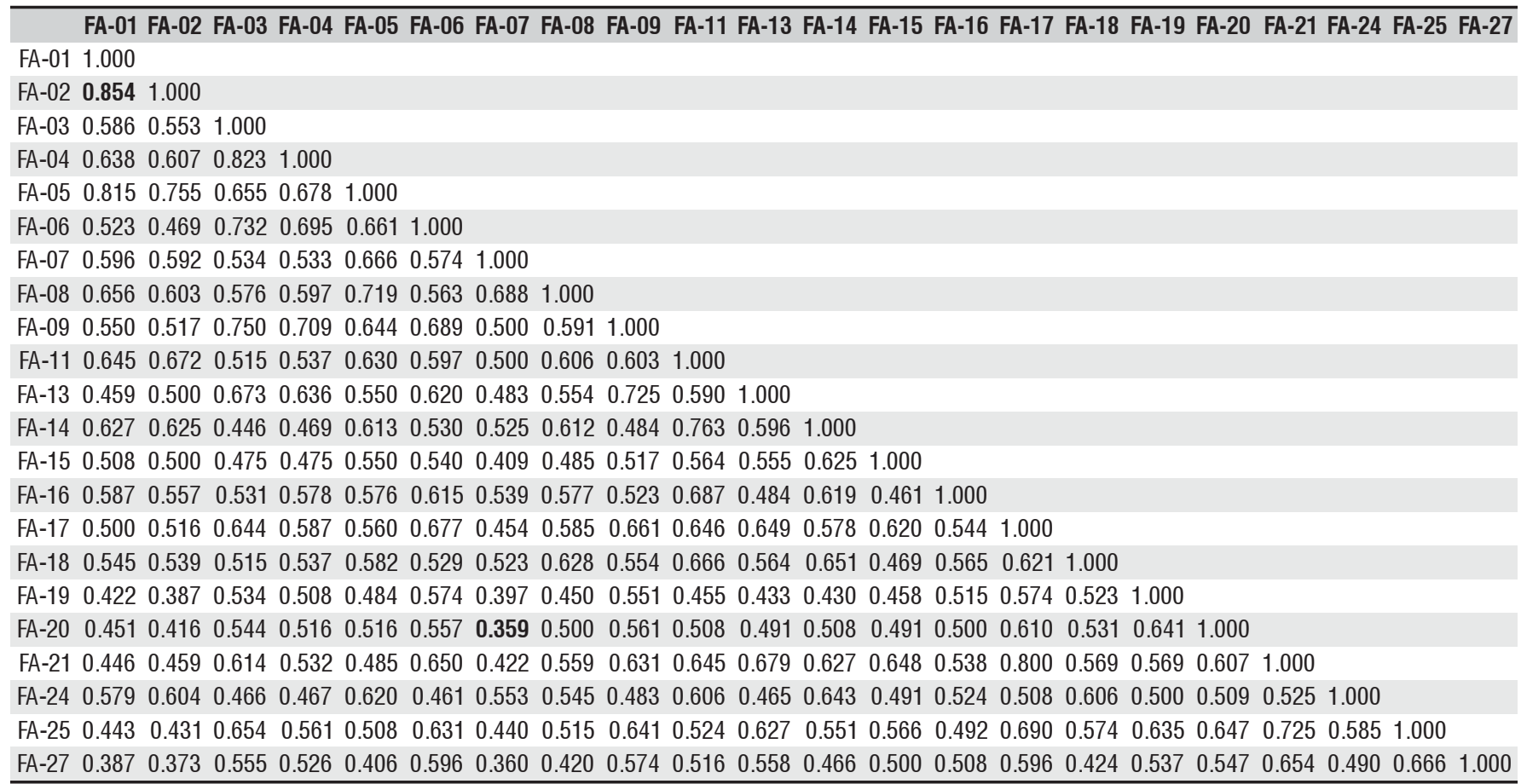


Tabela 4. Características morfoagronômicas* de 14 acessos de feijão-fava da Coleção de Germoplasma do Departamento de Agronomia da UFRPE

\begin{tabular}{|c|c|c|c|c|c|c|c|c|c|c|c|c|}
\hline \multirow{2}{*}{ Acessos } & \multirow{2}{*}{$\begin{array}{l}\text { Hábito de } \\
\text { Crescimento }\end{array}$} & \multicolumn{5}{|c|}{ Características das folhas } & \multicolumn{5}{|c|}{ Características do caule } & \multirow{2}{*}{ Cor da flor } \\
\hline & & FF & $F$ & BLF & TLF & AF $\left(\mathrm{cm}^{2}\right)$ & CC & PC & DC (cm) & NUP & NRP & \\
\hline FA-01 & I & BA & VC & $\mathrm{L}$ & C & 43,55 & VSP & $P$ & 0,74 & 14 & 5 & B \\
\hline FA-03 & I & BA & VN & L & C & 41,68 & VPT & $\mathrm{P}$ & 0,80 & 14 & 6 & B \\
\hline FA-07 & I & BA & VN & L & C & 58,88 & VPT & $P$ & 0,92 & 13 & 5 & BA \\
\hline FA-08 & 1 & LA & VE & $\mathrm{L}$ & C & 33,92 & VPT & $\mathrm{P}$ & 0,97 & 12 & 5 & $A B$ \\
\hline FA-09 & I & BA & VN & $\mathrm{L}$ & C & 32,93 & VSP & $P$ & 0,95 & 12 & 5 & BA \\
\hline FA-11 & 1 & BA & VN & L & C & 34,43 & VSP & $P$ & 0,67 & 13 & 4 & BA \\
\hline$F A-13$ & I & A & VN & L & C & 35,68 & VPT & $P$ & 1,01 & 12 & 6 & $\mathrm{~L}$ \\
\hline FA-16 & I & LA & VN & $\mathrm{L}$ & C & 52,79 & VSP & $P$ & 0,59 & 15 & 4 & $\mathrm{~L}$ \\
\hline FA-17 & I & LA & VN & L & C & 38,64 & VPI & $P$ & 1,02 & 10 & 4 & B \\
\hline FA-18 & 1 & $A$ & VN & L & C & 31,28 & VSP & $P$ & 0,87 & 15 & 6 & B \\
\hline FA-19 & D & BA & VE & $\mathrm{L}$ & C & 36,36 & VSP & $P$ & 0,80 & 04 & 5 & B \\
\hline FA-20 & I & LA & VN & L & C & 28,40 & VSP & $P$ & 0,85 & 13 & 7 & L \\
\hline FA-25 & I & LA & VN & $\mathrm{L}$ & C & 49,80 & VSP & $P$ & 0,87 & 12 & 5 & $\mathrm{~L}$ \\
\hline FA-27 & 1 & BA & VC & $\mathrm{L}$ & C & 45,00 & VPI & $\mathrm{P}$ & 1,34 & 13 & 4 & $\mathrm{~L}$ \\
\hline
\end{tabular}

* Hábito de crescimento: I (Indeterminado) e D (Determinado); Características das folhas: FF- Forma Folha (BA- Bruscamente Acuminada; LA- Longamente Acuminada; A- Acuminada); F- Cor Folha (VCVerde Claro; VN- Verde Normal; VE- Verde Escuro); BLF- Bordas da Lâmina Foliar (L-Lisa); TLF- Textura da Lâmina Foliar (C-Coriácea); AF - Área Foliar; Características do caule: CC- Cor Caule (VPT- Verde com Pigmentacão Tênue; VSP- Verde Sem Pigmentação; VPI- Verde com Pigmentação Intensa); PC- Pêlos Caule (P-Piloso); DC- Diâmetro Caule; NUP- Número de nós até 1 metro da Planta; NRP- Número de nós até o Ramo Principal; Cor da Flor (B- Branca; BA- Branca/Amarela; AB- Amarela/Branca; L- Lilás)

caracterizado pelo desenvolvimento da gema terminal em uma guia e trepador; apenas o genótipo FA-19 apresentou hábito determinado, caracterizado pelo desenvolvimento completo da gema terminal em uma inflorescência. Esta característica é monogênica, com dominância do alelo que condiciona o crescimento indeterminado. Santos et al. (2002), estudando produtividade e morfologia de vagens e sementes de variedades de fava no Estado da Paraíba, notaram que todos os genótipos indicaram hábito de crescimento indeterminado e trepador. Oliveira et al. (2004), ao analisarem a produção de feijão-fava em função da nutrição mineral, constataram que no Nordeste brasileiro os pequenos produtores utilizam principalmente cultivares de crescimento indeterminado corroborando, assim, com os resultados observados neste trabalho.

Quanto às características das folhas, a forma da folha (FF), herança monogênica, verificada apenas nos folíolos centrais de folhas completamente desenvolvidas, nos genótipos FA-13 e FA-18, foram do tipo acuminada (A), nos genótipos FA-08, FA-16, FA-17, FA-20 e FA-25 foram do tipo levemente acuminada (LA) e, nos demais genótipos, apresentaram forma da folha bruscamente acuminada (BA). Em relação à cor das folhas (F), os genótipos FA-08 e FA-19 mostraram-se verde escuro (VE), os genótipos FA-01 e FA-27 verde claro (VC) e os demais genótipos indicaram coloração verde normal (VN). As bordas da lâmina foliar (BLF) apresentaram-se lisas (L) para todos os genótipos, enquanto a textura da lâmina foliar (TLF) foi do tipo coriácea. Os genótipos exibiram área foliar (AF) variando de $28,40 \mathrm{~cm}^{2}$ (FA-20) a 58,88 $\mathrm{cm}^{2}$ (FA-07).

A pilosidade (PC), que varia segundo a cultivar, a parte da planta, o estádio de crescimento e, em menor grau, com as condições ambientais, como seca e luz, todos os genótipos avaliados apresentaram pilosidade. A cor do caule (CC), variou de verde sem pigmentação (VSP) para os genótipos FA-01, FA-09, FA-11, FA-16, FA-18, FA-19, FA-20 e FA-25, verde com pigmentação tênue (VPT) para os genótipos FA-03,
FA-07, FA-08 e FA-13, e verde com pigmentação intensa (VPI) para os demais. O diâmetro do caule principal (DC) variou de $0,59 \mathrm{~cm}$ (FA-16) a 1,34 cm (FA-27). O número de nós no caule até $1 \mathrm{~m}$ (NUP) variou de 4 em FA-19 até 15 em FA-16 e FA-18, e até o ramo principal variou (NRP) de 4 (FA-11, FA-16, FA-17 e FA-27) a 7 (FA-20).

A cor da flor varia consideravelmente de acordo com o momento do dia em que se faz a observação, razão pela qual sua identificação foi efetuada sempre nas primeiras horas da manhã, já que a luz solar produz rapidamente uma diminuição nos tons das cores (Romero, 1961). Observaram-se quatro variações de cores das flores, a saber: branca (FA-01, FA-03, FA-17, FA-18 e FA-19), lilás (FA-13, FA-16, FA-20, FA-25 e FA-27), branco/amarelado (FA-07, FA-09 e FA-11) e amarelo/branqueado (FA-08).

A cor do tegumento (CT) foi avaliada neste trabalho devido à importância dos diferentes tipos, tanto na aceitação no mercado como na identificação botânica. A ampla variabilidade de cores do tegumento das sementes (Figura 3) apresentada pelos diversos acessos de feijão-fava, é uma característica fundamental na identificação de cultivares. Os 14 acessos avaliados apresentaram os tegumentos com as seguintes tonalidades (Tabela 5): rajada branca com preta-RBP (FA-01); branca com manchas alaranjadas-BA (FA-03); branca-B (FA-07 e FA-27); vermelhaV (FA-08); branca com preta-BP (FA-09 e FA-13); rajada branca com vermelha-RBV (FA-11); vinho-VI (FA-16); rajada marrom com roxo-RMR (FA-17, FA-19 e FA-20); roxa com creme-RC (FA-18) e preta com creme-PC (FA-25). A cor do tegumento das sementes é um fator que pode contribuir para boa comercialização ou não do produto e isto dependerá da preferência dos consumidores nas diferentes regiões. Vera et al. (1999), conseguiram distinguir as classes comerciais de feijões chilenos, de acordo com a cor dos grãos.

Quanto ao peso de 100 sementes (PCS), os genótipos estudados apresentaram variação de 15,0 g (FA-16) a 88,89 g (FA-13). Azevedo et al. (2003) estudando oito variedades de feijão-fava, encontraram valores médios entre 47,39 g a 

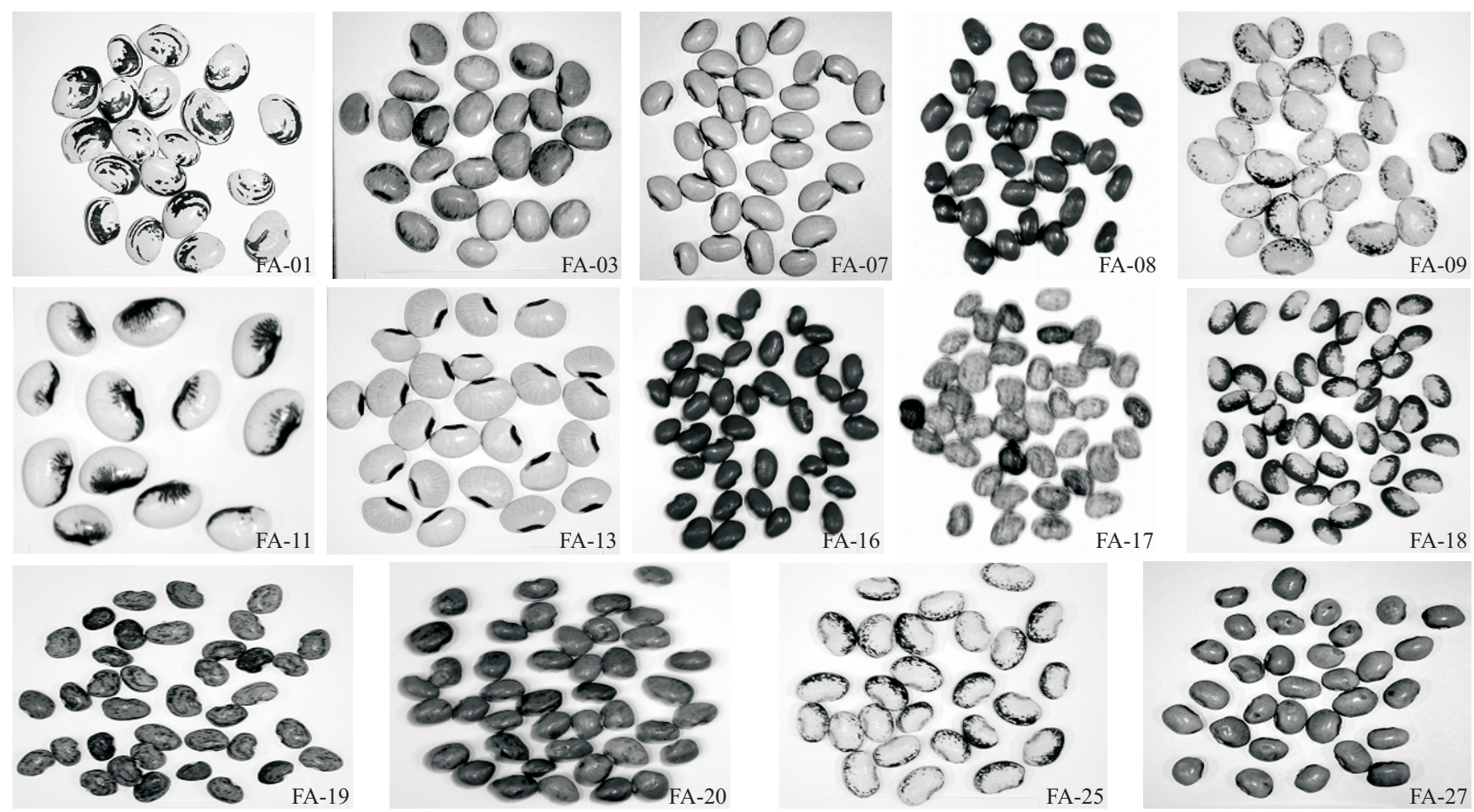

Figura 3. Formas, tamanhos e cores do tegumento dos 14 acessos de feijão-fava usados na caracterização morfoagronômica

$90,05 \mathrm{~g}$. As sementes foram classificadas, quanto ao tamanho (TS): em grande (maior que $60 \mathrm{~g}$ ), normal ( 40 a 59,9 g) e média (menor que $40 \mathrm{~g}$ ). Nos genótipos estudados predominaram sementes de médio a grande. $\mathrm{O}$ tamanho das sementes do feijão-fava pode ser uma característica significativa do ponto de vista de desenvolvimento fisiológico da cultura, já que Dobert \& Blevins (1993) verificaram que plantas desenvolvidas a partir de sementes maiores produziram mais nódulos e matéria seca de parte aérea que as oriundas de sementes menores, sugerindo maior fixação de nitrogênio atmosférico. Quanto ao coeficiente J (comprimento/largura), cujas sementes podem ser esféricas (1,16 a 1,42 mm), elípticas (1,43 a $1,65 \mathrm{~mm}$ ), oblongas ou reniformes curtas (1,66 a 1,85 mm), oblongas ou reniformes médias (1,86 a 2,00 mm) e oblongas ou reniformes longas (maior que 2,00 mm) (Vilhordo et al.,1996), o genótipo FA-20 apresentou sementes esféricas e os demais, sementes elípticas. Através da relação espessura/ largura $(H)$, todos os acessos avaliados apontaram sementes achatadas (menor que 0,69-mm). Em relação ao comprimento e largura dos grãos, respectivamente, os maiores valores foram de 16,9 e 11,7 mm (FA-13), 16,4 e 10,3 mm (FA-11), 16,2 e 11,0 mm (FA-17); já para espessura de grãos, a maior foi para o genótipo FA-13, com 6,1 mm.

O número de vagens por planta (NVP) variou de 14,4 (FA-16) a 436,3 (FA-18). Esta variabilidade apresentada é uma característica genética importante na identificação de genótipos potencialmente produtivos. Na cor da vagem (CRV), um tipo de herança monogênica, o verde uniforme, predominou em todos os genótipos e o número de sementes por vagem (NSV) oscilou, em sua maioria, de duas a quatro. Santos et al. (2002), estudando produtividade e morfologia de sementes de variedades de feijão-fava, também en- contraram a mesma variação para o número de sementes por vagem. Os genótipos FA-11 (89,5 mm), FA-13 (85,3 mm) e FA-17 (84,6 mm) apresentaram os maiores comprimentos de vagem $(\mathrm{CV})$, destacando-se dos demais. Em relação à largura da vagem (LV) e espessura da vagem (EV), a variação foi de 21,4 mm (FA-13) a 7,9 mm (FA-18), respectivamente. Quanto à produção de sementes por planta $(\mathrm{P})$, os genótipos FA-17, FA-11, FA-18 e FA-20 foram os mais produtivos, com 556, 795, 830 e 1500 g de sementes por planta, respectivamente.

Observou-se que o genótipo FA-13, proveniente do Ceará, se destacou dos demais em virtude de apresentar maiores valores para: peso de 100 sementes (88,89 g), número de sementes por vagem (2-6), comprimento de vagem (85,3 mm) e largura de vagem $(21,4 \mathrm{~mm})$; já o genótipo FA-16, oriundo de Pernambuco, indicou menores valores de peso de 100 sementes, com sementes muito pequenas, menor número de vagens por planta, menor comprimento de vagem e a menor produção de sementes por planta (Tabela 5).

A distribuição dos acessos analisados no dendrograma não foi capaz de separá-los por área de coleta, como já se esperava, pois os produtores dessas regiões, por estarem próximas geograficamente, trocam sementes entre si mas a avaliação de germoplasma tem sido muito otimizada pela junção de marcadores moleculares com descritores morfológicos, possibilitando avaliar a distância genética com base em características importantes para o melhoramento, como a escolha de linhas de parentais contrastantes.

Embora a similaridade genética entre os 22 acessos tenha sido calculada com base em dados moleculares que, muitas vezes, não correspondem a regiões expressas do DNA, os resultados apresentados são bastante consistentes em 
Tabela 5. Características morfoagronômicas de vagens e grãos de 14 acessos de feijão-fava da Coleção de Germoplasma do Departamento de Agronomia da UFRPE

\begin{tabular}{|c|c|c|c|c|c|c|c|c|c|c|c|c|c|c|c|c|}
\hline \multirow[b]{2}{*}{ Acessos } & \multicolumn{7}{|c|}{ Características das vagens } & \multicolumn{9}{|c|}{ Características dos grãos } \\
\hline & CRV & NVP & NSV & $\begin{array}{c}\mathrm{CV} \\
(\mathrm{mm})\end{array}$ & $\begin{array}{c}\mathrm{LV} \\
(\mathrm{mm})\end{array}$ & $\begin{array}{c}\text { EV } \\
(\mathrm{mm})\end{array}$ & $\begin{array}{c}P \\
\text { (g) }\end{array}$ & $\underset{(\mathrm{mm})}{\mathrm{C}}$ & $\underset{(\mathrm{mm})}{\mathrm{L}}$ & $\underset{(\mathrm{mm})}{E}$ & $\underset{(\mathrm{mm})}{\mathrm{J}}$ & $\underset{(\mathrm{mm})}{\mathrm{H}}$ & FS & PCS & TS & CT \\
\hline FA-01 & VU & - & - & - & - & - & - & - & - & - & - & - & - & - & G & RBP \\
\hline FA-03 & VU & - & - & - & - & - & - & - & - & - & - & - & - & - & G & BA \\
\hline FA-07 & VU & - & $2-3$ & 74,8 & 14,2 & 1,4 & - & 15 & 9,4 & 4,9 & 1,59 & 0,52 & $\mathrm{EA}$ & - & G & B \\
\hline FA-08 & VU & - & - & - & - & - & - & - & - & - & - & - & - & - & $\mathrm{N}$ & V \\
\hline FA-09 & VU & - & - & - & - & - & - & - & - & - & - & - & - & - & G & $\mathrm{BP}$ \\
\hline $\mathrm{FA}-11$ & VU & 77,0 & $2-4$ & 89,5 & 19,3 & 6,4 & 795 & 16,4 & 10,3 & 5,8 & 1,59 & 0,56 & $\mathrm{EA}$ & 85,34 & $\mathrm{G}$ & RBV \\
\hline FA-13 & VU & 18,7 & $2-6$ & 85,3 & 21,4 & 7,3 & 165 & 16,9 & 11,7 & 6,1 & 1,44 & 0,52 & EA & 88,89 & G & $\mathrm{BP}$ \\
\hline FA-16 & VU & 14,4 & $2-4$ & 48,6 & 13,9 & 6,2 & 56 & 11,3 & 7,4 & 5,2 & 1,53 & 0,70 & $\mathrm{EC}$ & 15,00 & MP & $\mathrm{Vl}$ \\
\hline $\mathrm{FA}-17$ & VU & 155,6 & $2-4$ & 84,6 & 16,5 & 4,4 & 556 & 16,2 & 11,0 & 5,0 & 1,47 & 0,45 & $\mathrm{EA}$ & 34,85 & $\mathrm{M}$ & RMR \\
\hline FA-18 & VU & 436,3 & $1-3$ & 55,1 & 13,5 & 7,9 & 830 & 12,4 & 8,0 & 5,0 & 1,55 & 0,62 & EA & 34,29 & $\mathrm{M}$ & $\mathrm{RC}$ \\
\hline FA-19 & VU & 42,2 & $1-3$ & 60,4 & 15,3 & 5,7 & 244 & 11,9 & 8,0 & 4,3 & 1,49 & 0,54 & $\mathrm{EA}$ & 37,31 & $\mathrm{M}$ & RMR \\
\hline FA-20 & VU & 317,2 & $2-4$ & 61,7 & 13,8 & 5,9 & 1500 & 11,3 & 8,0 & 4,7 & 1,41 & 0,59 & SA & 35,56 & $M$ & RMR \\
\hline FA-25 & VU & 42,2 & $2-4$ & 65,8 & 15,5 & 5,9 & 198 & 12,9 & 8,9 & 5,0 & 1,45 & 0,56 & $E A$ & 54,19 & $\mathrm{~N}$ & PC \\
\hline FA-27 & VU & - & - & - & - & - & - & - & - & - & - & - & - & - & $\mathrm{N}$ & B \\
\hline
\end{tabular}

Características das vagens: CRV- Cor Vagem (VU- Verde Uniforme); NVP- Número de Vagens por Planta; NSV- Número de Sementes por Vagem; CV- Comprimento de Vagem; LV- Largura de Vagem; EVEspessura de Vagem; P- Produtividade; Características dos grãos: C- Comprimento; L- Largura; E- Espessura ; J- Coeficiente Comprimento/Largura; H- Coeficiente Espessura/Largura; FS- forma da semente
(EA- Elíptica/Achatada; EC- Elíptica Semi-Cheia; SA- Esférica/Achatada); PCS- Peso de 100 Sementes; TS- Tamanho da Semente (G- Grande; M- Média; N- Normal; MP- Muito Pequena); CT- Cor do (EA- Eliptica/Achatada; EC- Elíptica Semi-Cheia; SA- Esférica/Achatada); PCS- Peso de 100 Sementes; TS- Tamanho da Semente (G- Grande; M- Média; N- Normal; MP- Muito Pequena); CT- Cor do
Tegumento (RBP- Rajada de Branca e Preta; BA- Branca com manchas Alaranjadas; B-Branca; V- Vermelha; BP- Branca com Preta; RBV- Rajada Branca com Vermelha; VI- Vinho; RMR- Rajada Marrom Tegumento (RBP- Rajada de Branca e Preta; BA- Branca
com Roxa; RC- Roxa com creme; PC- Preta com creme)

decorrência de não haver interferência do ambiente, o que é comum em dados fenotípicos; além disso, os marcadores RAPD geralmente proporcionam uma ampla cobertura do genoma. Os resultados gerados apresentam grande utilidade ao melhoramento de feijão-fava, pois permitem maior compreensão sobre a variabilidade genética da cultura e fornecem subsídios para programas de seleção de indivíduos.

Considerando-se que o feijão-fava é uma significativa fonte de proteína e de renda para a população menos favorecida da Região Nordeste e que tem, ainda, pouca relevância no Brasil, apesar de ser cultivada em maior ou menor extensão em todos os Estados, os resultados desta pesquisa fornecem subsídios para selecionar genótipos em programas de melhoramento e na escolha de progenitores complementares e/ou divergentes, objetivando maior eficiência para desenvolvimento de cultivares.

\section{CONCLUSÕES}

1. Através dos marcadores moleculares de RAPD foi possível constatar que não há acessos redundantes (iguais) na Coleção de Germoplasma de feijão-fava do Departamento de Agronomia da UFRPE.

2. Os primers OP-C15, OP-E02, OP-E04, OP-A18, C-O5 e C-O6, são indicados para análise da divergência genética em feijão-fava.

3. A variabilidade genética identificada nos germoplasmas de feijão-fava gerou informações que podem otimizar a manutenção e o manejo dos acessos, facilitando a obtenção de novos conjuntos gênicos aos melhoristas.

4. Os estudos da diversidade genética associados a características morfoagronômicas de feijão-fava da Coleção de Germoplasma da UFRPE, sinalizaram com acessos promissores para utilização em plantas comerciais.

\section{LITERATURA CITADA}

Azevedo, J. N.; Franco, L. J. D.; Araújo, R. O. C. Composição química de sete variedades de feijão-fava. Teresina: Embrapa Meio-Norte, 2003. 4p. Comunicado Técnico

Baudoin, J. P. Genetic resources, domestication and evolution of lima bean, Phaseolus lunatus. In: Gepts, P. (ed.). Genetic resources of Phaseolus bean. Amsterdam: Kluwer Academic Publishers, 1988, p.393-407.

Beebe, S. E.; Skroch, P. W.; Tohme, J.; Duque, M. C.; Pedraza, F.; Nienhuis, J. Structure of genetic diversity among common bean landraces of Middle America origin based on correspondence analysis of RAPD. Crop Science, Madison, v.40, n.1, p.264-273, 2000.

Bliss, F. A. Inheritance of growth habit and time of flowering in beans. Journal of the American Society for Horticultural Science, Alexandria, v.96, n.6, p.715-7, 1971.

Broughton, W. J.; Ernández, G.; Blair, M.; Beebe, S.; Gepts, P.; Vanderleyden, J. Beans (Phaseolus spp.) - model food legumes. Plant and Soil, Dordrecht, v.252, n.1, p.55-128, 2003.

Caicedo, A.; Gaitán, E.; Duque, M. C.; Toro Chica, O.; Debouck, D. G.; Tohme, J. AFLP fingerprinting of Phaseolus lunatus L. and related wild species from South America. Crop Science, Madison, v.39, n.5, p.1497-1507, 1999.

CIAT. Condiciones del campo para realizar las evaluaciones del germoplasma de frijol. Cali: [CIAT], 1976. 11p.

Dobert, R. C.; Blevins, D. G. Effect of seed size and plant growth on nodulation and nodule development in lima bean (Phaseolus lunatus L.). Plant and Soil, Dordrecht, v.148, n.1, p.11-19, 1993.

Doyle, J. J. T.; Doyle, J. L. Isolation of plant DNA from fresh tissue. Focus, Ithaca, v.12, p.13-18, 1990.

Eichenberg, K.; Gugerli, F.; Schneller, J. J. Morphological and molecular diversity of swiss common bean cultivars (Phaseolus vulgaris L. Fabaceae) and their origin. Botanica Helvetica, Basel, v.110, n.1, p.61-67, 2000. 
Ferreira, M. E.; Grattapaglia, D. Introdução ao uso de marcadores moleculares em análise genética. 3.ed. Brasília: EmbrapaCenargen. 1998. 220p.

Fofana, B.; Vekemans, X.; Jardin, du P.; Baudoin, J. P. Genetic diversity in lima (Phaseolus lunatus L.) as revealed by RAPD markers. Euphytica, Wageningen, v.95, n.2, p.157-165, 1997.

Freire Filho, F. R. Herança no número de dias para a floração e do hábito de crescimento em feijoeiro (Phaseolus vulgaris L.). Viçosa: UFV. 1980. 38p. Dissertação Mestrado

Halvankar, G. B.; Patil, V. P. Inheritance and linkage studies in soybean. Indian Journal of Genetic and Plant Breeding, New Delhi, v.54, n.3, p.216-224, 1994.

Khattak, G. S. S.; Haq, M. A.; Ashraf, M. Inheritance and joint segregation pattern of testa colour and plant growth habit in mungbean (Vigna radiate (L.) Wilczek). Tropical Agricultural Research and Extension, Weslaco, v.2, n.1, p.1-3, 1999.

Lioi, L.; Galasso, I. Oligonucleotide DNA fingerprinting revealing polymorphism in Phaseolus lunatus L. Genetic Resources and Crop Evolution. Bari, v.49, n.1, p.53-58, 2002.

Martins, L. S. S. Marcadores moleculares no estudo da resistência do feijoeiro comum (Phaseolus vulgaris L.) ao agente da mancha angular (Phaeoisariopsis griseola (Sacc.) Ferraris). Recife: UFRPE, 1999. 117p. Tese Doutorado

Martins, L. S. S.; Falcão, T. M. M.; Coelho, R. S. B. Identificação de marcadores RAPD ligados à resistência à mancha angular do feijoeiro comum. Summa Phytopatologica, Jaboticabal, v.30, n.2, p.234-237, 2004.

Miranda, C. S. Mejoramiento genético del fríjol. In: Brauer, O. Fitogenetica aplicada. Chapingo: Limusa, 1973. p.412-440.

Nienhuis, J.; Tivang, J.; Skrock, P.; Santos, J. B. Genetic relationships among cultivars and landraces of lima bean (Phaseolus lunatus L.) as measured by RAPD markers. Journal of the America Society for Horticultural Science, Alexandria, v.120, n.2, p.300-306, 1995.

Oliveira, A. P. de; Alves, E. U.; Alves, A. U.; Dornelas, C. S. M.; Silva, J. A. da; Porto, M. L.; Alves, A. V. Produção de feijão-fava em função do uso de doses de fósforo em um Neossolo Regolítico. Horticultura Brasileira, Brasília, v.22, n.3, p.543-546, 2004.
Oliveira, F. J.; Anunciação Filho, C. J. da; Bastos, G. Q.; Reis, O. V. dos; Teófilo, E. M. Caracteres agronômicos aplicados na seleção de cultivares de caupi. Revista Ciência Agronômica, Fortaleza, v.34, n.1, p.44-50, 2003.

Ospina, O. H. F. Morfologia de la planta de frijol comum (Phaseolus vulgaris L.). 2.ed. Cali: CIAT, 1981. 50p.

Rohlf, F. J. NTSYS-pc numerical taxonomy and multivariate analysis system: version 1.7. New York: Exeter Software, 1992. 236p.

Romero, J. P. Variedades de judias cultivadas en España. Madrid: Ministério da Agricultura, Pecuária e Abastecimento, 1961. 798p. Monografia

Santos, D.; Corlett, F. M. F.; Mendes, J. E. M. F.; Wanderley Junior, J. S. A. Produtividade e morfologia de vagens e sementes de variedades de fava no Estado da Paraíba. Pesquisa Agropecuária Brasileira, Brasília, v.37, n.10, p.14071412, 2002.

Sax, K. Quantitative inheritance in Phaseolus. Journal of Agricultural Research, Beltsville, v.33, n.4, p.349-354, 1926.

Singh, S. P. Broadening the genetic base of common bean cultivars: a review. Crop Science, Madison, v.41, n.6, p.16591675, 2001.

Vera, C. M.; Paredes, M. C.; Becerra, V. V. Estudo comparativo de diversidad morfológica, isoenzimatica y RAPDs dentro y entre clases comerciales de frijol chileno (Phaseolus vulgaris L.). Agricultura Técnica, Santiago, v.59, n.4, p.247-259, 1999.

Vieira, C. Leguminosas de grãos: importância econômica na agricultura e na alimentação humana. Informe Agropecuário, Belo Horizonte. v.16, n.174, p.5-11, 1992.

Vilhordo, B. W.; Araújo, R. S.; Rava, C. A.; Stone, L. F.; Zimmerman, M. J. de O. Morfologia. In: Araújo, R. S.; Rava, C. A.; Stone, L. F.; Zimmerman, M. J. de O. Cultura do feijoeiro comum no Brasil. Piracicaba: Potafos, 1996. p.71-99.

Vilhordo, B. W.; Müller, L. Correlação entre caracterização botânica e classificação comercial em cultivares de feijão (Phaseolus vulgaris L.). Porto Alegre: Embrapa CPAFRO, 1981. 62p. Boletim Técnico 8 